\title{
Hegel and Schopenhauer as Partisans of Goethe's Theory of Color
}

P. F. H. Lauxtermann

It sometimes happens in the history of ideas that two personalities, both of whom are regarded by posterity as typical representatives of their age, were during their own lifetimes unaware of any common ground and perhaps even viewed each other with hostility because of certain differences in outlook, which we would today regard as trifles or at least as matters of minor importance. In the seventeenth century we see an example of this in Pierre Bayle's attitude towards Spinoza. Their common opposition to intolerance, superstition, and absolutism in state and church did not prevent Bayle from speaking with horror and contempt of Spinoza's philosophy: "la plus monstrueuse hypothèse que se puisse imaginer, la plus absurde et le plus diamétralement opposée aux notions les plus distinctes de l'esprit humain." Or take Lessing's attitude towards Voltaire in the Age of Enlightenment: the "German Voltaire," as Lessing is sometimes called (not without justice), hated his French counterpart because the latter failed to appreciate Shakespeare and clung instead to the conventional rules of classicist theater. A similar case is offered in the first half of the nineteenth century by Arthur Schopenhauer's bitter invectives against the "charlatan" and "frecher Unsinnschmierer" Hegel, who, on his side, consistently ignored his somewhat younger contemporary. It is now generally admitted that, at least with the two other main representatives of German Idealism, Fichte and Schelling, Schopenhauer had more in common than he would himself have been ready to admit. And though it is certainly true that his differences with Hegel were of a more profound nature, ${ }^{2}$ both passionately took sides with Goethe in the latter's notorious polemic against Newton's Opticks.

One might argue that we have to do here with a mere coincidence because the theory of color was only a relatively unimportant issue in

${ }^{1}$ Paul Hazard, La Crise de la conscience européenne, 1680-1715 (Paris, 1961), 133.

${ }^{2}$ Cf. Bryan Magee, The Philosophy of Schopenhauer (New York, 1983), $259 \mathrm{ff}$.

Copyright 1990 by Journal OF THE History OF IDEAS, INC. 
the work of both thinkers. Yet such an argument would overlook the symptomatic importance of the issue, since there was much more at stake here than only a controversy about one particular scientific hypothesis. All the differences that exist between Goethe's scientific outlook and the romantic German Naturphilosophie of his time, important as they are, ${ }^{3}$ cannot conceal their common root in the rejection of the mechanicist view of nature and in the ardent desire to replace it with a conception of Nature as a dynamic Whole, dominated by the twin principles of Polarität and Steigerung. The former means that Nature works through antagonisms that are not mutually exclusive but rather supplementary and possessing an underlying unity. The latter means that Nature is possessed by an inner tendency towards ever higher and more complex forms. The most typical representative of Naturphilosophie was Schelling (at least at one stage of his Protean philosophical development), and it is therefore interesting to compare Hegel's and Schopenhauer's reception of Schelling's doctrines and to take this as a starting-point for an attempt to point at some similarities in their philosophical positions-similarities which tend to be overlooked by their respective admirers but which might help to explain how these apparent antipodes could both take sides with Goethe against Newton. When we examine in some detail their respective contributions to the theory of color, however, we shall see the profound differences in the way they defended an apparently common cause. The concluding section of this paper is devoted to a critical comparison between their respective philosophical attitudes insofar as these may help to explain such differences.

\section{Hegel and Schopenhauer on Schellingianism}

It will not surprise anybody that Schopenhauer rejected Schelling's philosophy at all its stages, since he rejected German Idealism as a whole. Schopenhauer's main objection to German Idealism was that it had betrayed Kant's critical heritage by confusing what Kant had neatly separated ("phenomenon" and "thing-in-itself," the "ideal" and the "real," etc.) in order to gain knowledge about the "Absolute," thus deliberately sanctioning deep-seated religious and popular prejudices. Therefore, he rejected Schelling's "philosophy of identity" (in which the earlier "philosophy of nature" may be said to have reached its logical conclusion) no less than his later so-called "positive philosophy" (not to be confused with its Comtean namesake), with its teleological interpretation of history as a kind of theogony. Nevertheless, despite his denial, Schopenhauer probably was influenced by Schelling to some extent. On the other hand, the notion of the Absolute in the form Schelling had given it was criticized by Hegel

${ }^{3}$ Cf. Alfred Schmidt, Goethes herrlich leuchtende Natur. Philosophische Studie zur deutschen Spätaufklärung (Munich, 1984), 110-34. 
as well. Although Schelling is not explicitly mentioned in the famous "Preface" to Hegel's first major work, the Phenomenology of Spirit, it is clear that the Identitätsphilosophie of his former friend, fellow student, and in a sense predecessor, ${ }^{4}$ is the target of the ironical remark about the "night in which all cows are black."

In this Preface Hegel is constantly fighting on two fronts: against "empty broadness" and against "empty profundity." Whereas the former (its typical representative being the Enlightenment) only gathers material without ordering it, the latter (represented by Romanticism) wants to look immediately into the depths of the Absolute but, in doing so, produces only "artefacts that are neither fish nor fowl, neither poetry nor philosophy." ought not to content itself with subjective intuition and vague feeling. Hegel therefore criticizes Schelling's beloved "intellectual intuition" just as Kant had already done in anticipation ${ }^{7}$ and as Schopenhauer did repeatedly. Schopenhauer mocks the "sixth sense of the bats," which he does not claim to possess ${ }^{8}$ and ironically confesses that he belongs to those "profanes" who completely lack "Vernunft-Anschauung" and must therefore refrain from giving their readers the latest pieces of news about the Absolute. ${ }^{9}$ Hegel, on the other hand, agrees with the prophets of "Vernunft-Anschauung" as far as the essential unity of Being and Thinking is concerned; but for him "it is essential to know whether this intellectual intuition does not relapse into inert simplicity and does not picture reality itself in an unreal way." 10 The difference should be clear: a holistic vision is for Hegel possible in principle (while for Schopenhauer it is not), but it should be reached in a "scientific" way and not through unreflected "intuition." Thus both reject Schelling's more thorough-going and romantic holism; indeed neither Hegel nor Schopenhauer (for different reasons) was a romantic Nature-worshipper. For this reason it may be expected that both thinkers had a more positive appreciation of science than was displayed by romantic Naturphilosophie. This is indeed true insofar as the empirical aspect of science is concerned. Both were reasonably well acquainted with the science of their time and both accorded it a legitimate, if restricted, role. As we shall see in the next section, both the legitimacy

${ }^{4}$ Though Hegel was five years older than Schelling, the latter's amazing philosophical precocity seems to justify this qualification; and it is certainly in agreement with Schelling's own opinion.

${ }^{5}$ G. W. F. Hegel, Werke in zwanzig Bänden (Frankfurt a. M., 1971), III, 22, translations mine. Cited hereafter as $H W$.

${ }^{6}$ Ibid., 64.

${ }^{7}$ Cf. Kants Werke, III (Berlin, 1968), 72.

${ }^{8}$ Arthur Schopenhauer, Sämtliche Werke, ed. Arthur Hübscher (Wiesbaden, 194850), II, 618, translations mine. Cited hereafter as $S S W$.

${ }^{9}$ Ibid., 30f.

${ }^{10} \mathrm{HW}$, III, 23. 
and the restrictions are emphasized in several of their writings, and this combination sheds interesting light on the philosophical background of their anti-Newtonianism.

\section{Hegel and Schopenhauer as Positivist Metaphysicians}

Hegel's lectures on the history of philosophy contain a remarkable passage where "Baco und Böhm" are hailed as the twin fathers of modern philosophy. Why this, at first glance rather odd, combination? Because, according to Hegel, these two men have put forward between them the two fundamental principles of any systematic science. It is the great merit of the theosophus teutonicus, Böhme, that he (in a barbaric language, alas, and with too little philosophical refinement) held firmly to the idea of the absolute divine unity and the union of all objects in God. ${ }^{11}$ Since, however, the life of spirit is connected not only with the abstract idea but also with empirical nature, it is essential to have knowledge of particular finite beings as well. ${ }^{12}$ Bacon's De augmentis scientiarium presents a systematic encyclopedia of the sciences, and his second work, Novum Organon, defends a new method of knowing opposed to the previous scholastic method of knowing by demonstration. Bacon pointed to the need of explaining Nature rather than arguing from concepts without regard for reality (what he called anticipationes naturae). ${ }^{13}$

Schopenhauer, on his side, nowhere explicitly juxtaposes "Baco und Böhm," but he mentions the shoemaker from Görlitz often and with due respect, the first time in a comment upon Schelling's Ueber die Freiheit which he made when still a student: "Why are the same images, forms and expressions that I read in Jakob Böhme with admiration and emotion, unbearable and ridiculous to me in Schelling? Because I perceive that in Jakob Böhme it is knowledge of eternal truth which expresses itself in these images. . .; Schelling, however, . . takes from him only what he can: the same images and expressions, without understanding their meaning." 14 Much later he reproaches Schelling for having appropriated Böhme's thought without mentioning his source. ${ }^{15}$ In his lectures Schopenhauer praises Bacon for much the same reasons as his philosophical rival had done. Bacon has shown the right way between the two errors of Scholasticism and Cartesianism, a way culminating in Newton (but not the Newton of the Opticks.) Scholasticism, instead of searching for the original and irreducible properties and forces through experience and experiment, im$227 \mathrm{f}$

${ }^{11}$ G. W. F. Hegel, Vorlesungen über die Geschichte der Philosophie, III (Leipzig, 1971),

${ }^{12}$ Ibid., 206.

${ }^{13}$ Ibid., 209.

${ }^{14}$ Arthur Hübscher, Denker gegen den Strom. Schopenhauer: Gestern-Heute-Morgen (Bonn, 1982), 45, my translation.

${ }^{15}$ Ibid. 
mediately, as mere epigones of Aristotle, invoked forma substantialis and qualitates occultae providing, instead of explanations, nothing but barbarous Latinisms (a tree is a tree by its arboreitas, bread is bread by its paneitas, etc.). Cartesianism lapsed from one extreme into the other by wishing to explain all natural phenomena by the laws of mechanics. According to Cartesian dualism no original properties existed in the objects at all but all were derived from those properties that belong to the objects as such, i.e., hardness, impenetrability, and the passing-on of motion. ${ }^{16}$

Here we have in a nutshell all elements that from then on were to characterize Schopenhauer's attitude towards science. He distrusted its rationalism, which had not only methodological but also ontological pretensions and which provides nothing but a poor, oversimplified worldview in which everything is reduced to mechanics. Yet Schopenhauer also had respect for the empirical aspect of science, which for him should be supplemented by a metaphysics of Nature better and richer than what is offered as such by mechanicist philosophy. It is not basically different with Hegel. Already in the Phenomenology of Spirit and later in the third part of the Encyclopedia he presents us with his view of the development of human knowledge. Knowledge begins with "sense-certainty," which is the state of mind at which we enjoy direct acquaintance with the object, and proceeds by interpreting the flux of sense-impressions as permanent properties of a thing: this is the level of "perceptual consciousness." But the thing can express and reveal what it is only in the way in which it behaves towards other things, and with this insight we have reached the level of "scientific understanding": the realm of things is now transformed into a realm of forces. Now forces are unobservable entities that become manifest only in the way in which they work, and so the realm of forces is essentially a realm of laws, which connect various types of phenomena and explain their changes. The essence of the force is nothing more than the content of the law. All explanation of empirical science can therefore never be more than the transformation of sense-appearance into the ideal form of laws: "the stable image of unstable appearances," "the quiet model of the perceived world," the "tranquil Kingdom of Laws." ${ }^{17}$ Empirical science provides us only with an orderly description of the phenomena we wish to explain; therefore, the level of understanding (Verstand) should be transcended in its turn. It is only when, by way of self-consciousness, we have reached the level of Reason (Vernunft), that absolute knowledge becomes possible.

Schopenhauer certainly did not believe in the possibility of "absolute knowledge"; but he did believe that "metaphysics of nature" can at least

${ }^{16}$ Arthur Schopenhauer, Philosophische Vorlesungen, Teil II, ed. Volker Spierling (Munich, 1984), 133f.

${ }^{17} \mathrm{HW}, \mathrm{III}, 120$. 
give us a deeper insight than mere "aetiology of nature," which, as he says in The World as Will and Representation, gives us no real explanation of the world. For at the end of its voyage it always encounters a qualitas occulta, which it calls a "force of nature" and of which it can only demonstrate the invariable constancy of its appearance as soon as certain conditions are fulfilled; and this constancy it calls a "law of nature." Therefore, even if aetiology has achieved all it can achieve, the philosophically-minded scientist still feels himself "like somebody, who, he knows not how, has turned up in a company completely unknown to him, whose members, each in his turn, present the next one as his friend or his cousin, as if by doing so, he has sufficiently introduced the other; he himself, however, would meanwhile (assuring again and again to be glad to meet the introduced person) always have the unexpressed question on his lips: 'but how, the deuce, have I come into this whole company?' "18

In short Hegel and Schopenhauer agree that, with the formulation of laws of nature, the task of science is completed and that it is up to the philosopher to look further and, like Faust, to search for "was die Welt im Innersten zusammenhält." Science has to do the preliminary work for philosophy, and this is both its justification and its limitation. Ironically enough, their view of science as an enterprise essentially confined to the description of functional relationships between natural phenomena brings our two metaphysicians in close vicinity of later nineteenth-century positivism. The difference is of course that positivists like Mach made a virtue out of necessity by proudly confining themselves to the "how" and dismissing all search for the "what" as senseless and irrelevant. Schopenhauer and Hegel, by contrast, present us with a two-layer model, whereby positivistically understood science is augmented by a kind of metaphysical superstructure. No doubt Schopenhauer's "superstructure" is quite different from Hegel's, but it is the "two-layer model" which distinguishes the two of them from earlier romantic Naturphilosophie.

There is one difficulty with this neat division of labor between science and philosophy. Actually existing science persistently refuses to be locked up into the positivist prison and indeed would not have made any progress, had it complied with the demands of positivists and of German metaphysicians and renounced its right to seek in its own way for "was die Welt im Innersten zusammenhält." Conflicts of competence may therefore reasonably be expected to result from the "two-layer model," as is shown indeed by Hegel's and Schopenhauer's attitude toward Newtonian science. A closer inspection of this attitude will at the same time bring to light an important difference in degree between their respective positions. But first we shall have to pursue a little further our inquiry into what these positions had in common.

${ }^{18} \mathrm{SSW}, \mathrm{II}, 117$. 
Hegel, Schopenhauer, and the Hierarchy of Sciences

Given the crucial role of mathematics in modern science, it is interesting to examine Hegel's and Schopenhauer's appreciation of this intellectual activity. Here again we see a remarkable resemblance. Hegel, in the "Preface," accuses mathematical knowledge of being arbitrary, since it cannot give reasons for why the proof is given in such-and-such a way and not otherwise. Besides, the subject-matter of mathematics is poor, since it is wholly homogeneous and uniform and leaves no room for diversity. Therefore, mathematical knowledge is purely formal, and as far as arithmetic is concerned, it is tautological (he does not use this expression, but it seems a not too arbitrary paraphrase of Hegel's interpretation of arithmetic as having merely to do with "the one"). ${ }^{19}$ Schopenhauer, in his turn, criticizes the mathematical method of demonstrating immediately evident things in a formally logical way and of comically surrendering when this is not possible (referring here to the dispute about the theory of parallels and the repeated attempts to prove Euclid's eleventh $\operatorname{axiom}^{20}$ ). Not that either Hegel or Schopenhauer saw no place for mathematics in science. Of course they did; but they would insist that its usefulness is greatest in those fields which are almost purely formal, that is, which are poor in empirical content. Or to put it in Schopenhauer's words, "Applied mathematics, i.e., mechanics, hydraulics etc., has to do with the lowest levels of the objectivation of Will, where most still belongs to the realm of pure Representation, but where there is nevertheless already an empirical element which obscures the complete intelligibility and transparency [of pure mathematics] and with which something inexplicable is introduced. For the same reason only a few parts of physics and chemistry still lend themselves to mathematical treatment; higher up in the chain of being this ceases precisely because the content of the phenomenon here outweighs the form." 21

Here we are at the heart of the matter. What Schopenhauer suggests here is the conception of a hierarchy of sciences, based upon the richness of their subject-matter and corresponding to a similar hierarchy in nature according to the different levels of "objectivation of Will," i.e., upon the different levels of complexity of natural phenomena. In the second volume of The World as Will and Representation this suggestion is elaborated into

${ }^{19} \mathrm{HW}$, III, 44. In his Science of Logic Hegel holds-against Kant, and in this foreshadowing Frege c.s. - that arithmetical propositions of the type $7+5=12$ are purely analytical (cf. Georg Wilhelm Friedrich Hegel, Sämtliche Werke. Jubiläumausgabe in zwanzig Bänden [Stuttgart, 1965], IV, 249f.). Schopenhauer, who thinks that they are synthetic a priori and have to do with time (Hegel denies that there is a "science of time corresponding to geometry, the science of space;" cf. HPN, I, 233), is here the orthodox Kantian.

${ }^{20}$ SSW, III, $142 \mathrm{f}$.

${ }^{21} S S W$, IV, 86. 
a schema that calls to mind the architecture of Hegel's Encyclopedia. According to this schema, science proceeds from mathematics and logic via the sciences of dead nature (dominated by the notion of cause) to the sciences of living nature (dominated by the notion of stimulus) and finally to the sciences of human mind and culture (dominated by the notion of motive). The parallel with Hegel's Encyclopedia, which starts with the Science of Logic, proceeds from there to the Philosophy of Nature (beginning with "mechanics" and ending with "organic physics") and culminates in the Philosophy of Spirit, is obvious. Both start from the most abstract form and look next to the progressively richer and more complex forms in which their metaphysical principle ("will" and "idea" respectively) objectivates itself in the concrete world.

What is striking in this idea of hierarchy of sciences is that (to use Kuhn's distinction ${ }^{22}$ ) the "classical physical sciences" rank lower on the scale than the "Baconian" sciences. But this is only what could be expected, given both Hegel's and Schopenhauer's depreciation of mathematics, which they, too, accorded an essential function in the former group. It is a commonplace that the most distinctive feature of the classical sciences was their growing claim to be able to describe physical reality in mathematical language, with all the metaphysical implications this involved. It is precisely against this "mechanization of the world-picture" and against the separation between Man and Nature that seems to follow in its wake that Naturphilosophie raised its romantic protest. As we have tried to show, this protest was somewhat "deromanticized" by the greater stress that was laid by philosophers like Hegel and Schopenhauer on the value of the empiricist, "Baconian" tradition in science. Yet in regard to the rapid mathematization of the "Baconian" sciences, which began in their very lifetime, this was of little consequence. ${ }^{23}$ Their oppositional attitude towards the scientific establishment is most conspicuous in their common rejection of Newtonianism, the difference being that Schopenhauer rejected only the Newton of the Opticks, while praising the Newton of the Principia. True, he thinks it necessary to inform the reader that already before Newton the theory of gravitation had been formulated by Robert Hooke, and he attributes the "idolatrous veneration" of Newton in England to people's being traditionally over-impressed by astronomy (typical once more for his relatively low opinion of the "classical" sciences). ${ }^{24}$ Yet he readily acknowledged the progress made by the Principia in this domain. For whereas Kepler had only pronounced the actual relation between the distance of a planet from the sun and the velocity of

${ }^{22}$ Cf. Thomas Kuhn, "Mathematical versus Experimental Traditions in the Development of Physical Science," The Essential Tension: Selected Studies in Scientific Tradition and Change (Chicago, 1977), 31-66.

${ }^{23}$ Ibid., 61.

${ }^{24}$ SSW, VI, 134. 
its orbit, Newton demonstrated that and why it had to go in this manner; "namely, because with this given distance to the central body the planet must have exactly this particular velocity in order not to fall into the sun or to run away from it."25

With Hegel it is otherwise. To him, all that is sound in Newton comes from Kepler, the only difference between the two men being that "what Kepler expressed in a simple and sublime manner as constituting the laws of celestial motion, is changed by Newton into the reflective form of the force of gravity." 26 By neglecting the fundamental distinction between mathematical analysis and physical reality Newton saddled physical mechanics with a "monstrous metaphysics, which, contrary to both experience and the Notion [Begriff], has its sole source in these mathematical demonstrations." 27

In all fairness to Hegel it should be acknowledged that popular Newtonianism in his times tended indeed to attribute metaphysical status to the forces treated in the Principia, but Hegel could have known that Newton himself was much more cautious in this respect. Though Newton certainly considered his "forces" as really existing and not only as a means of measurement, he did not "frame hypotheses" about the ultimate reality behind them. ${ }^{28}$ For Schopenhauer this was apparently modest enough, but not so for Hegel. One wonders whether he would have liked to return to the Ptolemaic situation of a complete separation between mathematical astronomy and physical astronomy. His predilection for ideas that were already hopelessly antiquated in his own day might make us believe so. (He also reproached Newton for having confused the "absolutely free movement" of the heavenly bodies with the "relatively free movement" of falling objects on earth, ${ }^{29}$ and he stuck firmly to the four traditional elements.) However, if this were the whole truth, he should have rejected Kepler as well. Perhaps a key is to be found in his remark, that "the Germans have often looked on impassively while the English have assumed authority in this way." ${ }^{30}$ German nationalism (of which Schopenhauer was conspicuously free) may have played tricks on Hegel here.

Be that as it may, Hegel and Schopenhauer agreed in rejecting the

${ }^{25}$ Ibid., 144.

${ }^{26}$ M. J. Petry (ed.), Hegel's Philosophy of Nature, tr. M. J. Petry (London, 1970), I, $264 f$.

${ }^{27}$ Ibid. Cf. also Frans H. van Lunteren, "Hegel and Gravitation," Hegels Philosophie der Natur, ed. Rolf-Peter Horstmann and Michael John Petry (Stuttgart, 1986), 45-53.

${ }^{28}$ On a relevant question of Bentley, Newton answered that, although he could calculate and describe it mathematically, he could not make statements about the physical reality behind these calculations (quoted by M. J. Petry in Hegel und die Naturwissenschaften, ed. Michael John Petry [Stuttgart, 1987], 341).

${ }^{29}$ Cf. $H P N$, I, 262.

${ }^{30} H P N$, I, 272. 
Opticks and taking sides with Goethe against Newton in the controversy about the nature of color, though in instructively different ways.

\section{Goethe's Theory of Color}

As is well known, Goethe's main objection to Newton was the latter's doctrine that white light is not simple but composed of rays of different refrangibility. This is not to say that, as is often suggested, Goethe was $a$ priori convinced that white light, since it appears as simple and pure to the eye, cannot be composite. In fact he had, like most people, taken the prevailing opinion for granted until the time that he started his own investigations in the field of optics. ${ }^{31}$ However, since then he had from his own experiments arrived at the conclusion that a boundary, a contrast, between light and dark is essential in the production of color phenomena, and this made it difficult for him to believe that colors are already contained in light as such. Nor, strictly speaking, did Newton; he only asserted that in what we perceive as white light, certain physical realities (i.e., light rays of different refrangibility) are present which have the power to provoke in us the sensation of the different colors. Nevertheless, his insistence on the role of light rays seemed to exclude the possibility that factors external to the light (e.g., the properties of the refracting medium) might contribute in an essential way to the appearance of colors. Now this is exactly what Goethe believed to be the case. He thought of color as a skieron, a kind of shadow, resulting from an interaction of light and darkness; and with that he placed himself in a long tradition going back to Aristotle. Goethe was aware, of course, that a simple mixture of light and darkness yields only grey, but he insisted that with the aid of a "turbid medium," such as smoke or mist, a combination can be effected that gives rise to color. Fortunately, all bodies are to some extent "turbid," which, he thinks, explains their particular color in daylight; these colors he calls chemische Farben and he labels them "objective" because they derive from a material substratum and are therefore permanent (although they may vary with varying light). But even transparent, refracting media have a certain "turbidity," so that the color phenomena produced by them also find a place in his theory. These he calls physische Farben, which have less objective reality because they are transient and fugitive; he therefore labels them "subjective-objective." Looking at darkness through a turbid medium gives the sensation of blue, whereas looking at light which comes

${ }^{31}$ Cf. Dennis L. Sepper, Goethe contra Newton: Polemics and the Project for a New Science of Color (New York, 1988), 27. For a critical evaluation of Goethe's place in the history of science and especially of his theory of color see also George A. Wells, Goethe and the Development of Science 1750-1900 (Alphen a/d Rijn, 1978); Frederick Burwick, The Damnation of Newton: Goethe's Color Theory and Romantic Perception (New York, 1986); Frederick Amrine, Francis J. Zucker, and Harvey Wheeler (eds.), Goethe and the Sciences: A Reappraisal (Dordrecht, 1987). 
through a turbid medium from a light-source behind it gives the sensation of yellow. In the first case there is darkness behind the medium, and the only light comes from a source in front or to one side of it; therefore, the light is not transmitted through the medium, but reflected from it.

From these two "polar opposites" all other colors can be derived through mixture or intensification (Steigerung). Since any color is eo ipso darker than white, its intensification must of necessity yield a still darker one. Thus intensified yellow (the brightest of colors) grades into the darker red, and intensified blue into the darkest of all colors, i.e., violet. Since the latter contains an element of redness, too, it may be said that both polar opposites intensify to a more or less reddish tint. Green, on the contrary, results from a mixture of the two primary colors. Finally, a mixture of their intensified forms produces "purple," which Goethe also refers to as the "true red," since it is produced by both lines of intensification together. What is normally called red (the red component of the spectrum) is, to Goethe, still a somewhat yellowish red. His "purple" is not exactly what is usually called "purple" either, but rather what we would nowadays call "magenta." When, in his "color circle," Goethe places "red" and green in a polar position, then, he is fairly in agreement with contemporary opinion. Goethe regarded the mixed nature of green as another argument against Newton because he did not realize that to mix pigments (chemische Farben) and to mix spectral colors (physische Farben) involves two fundamentally different processes. However, in justice to Goethe it should be mentioned that the difference between what we now call additive and subtractive color mixing, respectively, was not properly understood before Helmholtz's epochal investigations in the midnineteenth century.

Goethe severely criticized Newton's mode of experimentation. Newton, so he complained, subjected the phenomenon to completely artificial conditions in order to prove a preconceived theory. In the experimentum crucis Nature is truly crucified, ${ }^{32}$ or (to use another image) Nature is put on the rack to compel her to confess what the investigator had already beforehand decided upon. "But Nature is a steadfast and noble person, who stands by the truth, even under all pains. If it is otherwise stated in the protocol, then the inquisitor has misheard or the clerk has miswritten." 33 Newton's belief that an achromatic telescope was impossible was regarded by Goethe as a typical example of his prejudiced mind, and the actual construction of such a telescope by Hall and later by Dollond served him as a striking proof of the invalidity of Newton's entire theory. Goethe was aware of the argument that Newton had indeed been wrong in his assumption that all refracting materials disperse the prismatic colors in a constant proportion and that this does not refute the core of his theory,

${ }^{32}$ Goethes Werke, II. Abt., 4. Bd. (Weimar, 1894), 449.

${ }^{33}$ Goethes Werke, II. Abt., 2. Bd. (Weimar, 1890), 69. 
since one has to distinguish between refraction and dispersion. But he found this counter-argument a mere verbal trick, designed only to put Newton in the right after all. ${ }^{34}$

In his criticism of Newton Goethe always stressed the need of patient empirical investigation that ought not to be influenced by premature hypotheses, such as Newton's theory of refrangibility. But of course Goethe himself was not a naive empiricist either; his constant quest for the Urphänomen (a central concept not only in his theory of color but in his scientific work in general) is proof to the contrary. His own explanation of color phenomena (the turbid medium through which the polar opposites of Light and Darkness are reconciled: an Urphänomen if ever there was one) as much transcends pure experience as Newton's rays. The essential difference is that Goethe's type of explanation is of a qualitative rather than a quantitative nature; and with this reaction against mathematicism and mechanicism he comes, in spite of his greater commitment to concrete empirical reality (what might be called his "Baconian" trait), close to Schelling's romantic Naturphilosophie.

\section{Goethe and Hegel}

At first glance these two names form a rather curious combination. Just recall Mephistopheles' warning to Faust:

Ich sag es dir: ein Kerl, der spekuliert,

Ist wie ein Tier, auf dürrer Heide

Von einem bösen Geist im Kreis herum geführt,

Und rings umher liegt schöne grüne Weide. ${ }^{35}$

Goethe, who confessed to "lacking the organ for philosophy proper"36 was far from a voracious reader of Hegel's writings (nor, for that matter, of those of any philosopher other than Spinoza). Though the two men rather frequently communicated during the period when Hegel was a Privatdozent at Jena (1802-6), a position obtained partly through Goethe's mediation, Goethe did not react at all when Hegel sent him the Phenomenology of Spirit. Indeed we have an irate remark from Goethe about a passage on botany in the "Preface" of this work (which he wrongly attributes to the Preface of the Science of Logic). Goethe quotes: "The bud disappears when the blossom breaks through, and we might say that the former is refuted by the latter; in the same way when the fruit comes the blossom may be explained to be a false form of the plant's existence,

${ }^{34}$ Goethes Werke, III. Abt., 4. Bd. (Weimar, 1894), 203-6.

${ }^{35}$ Goethes Werke, ed. Ernst Merian/ Genast (Basel, 1944), III, 58. Indeed it is above all its speculative excesses which urged Goethe to keep a certain distance even from Schelling's Naturphilosophie, with which he had otherwise so much in common. Cf. Sepper, op.cit., 169.

${ }^{36}$ Goethes Werke in vierzehn Bänden (Hamburg, 1948-60), XIII, 25. 
for the fruit appears as its true nature in place of the blossom...." His reaction: "To say anything more monstrous is indeed not possible. It seems to me quite unworthy of a rational man to want to annihilate the eternal reality of nature by means of a miserable sophistical joke.... When a distinguished thinker manages to contradict and obliterate an idea by means of ingenious but mutually self-nullifying words and phrases, one knows not what to say." 37

However, Goethe's anger did not last long. Obviously, Hegel's public championship of Goethe's theory of color in his Encyclopedia (the first version of which dates from 1817), combined with the former's growing fame, contributed to the resumption of their broken contact, resulting in a friendly correspondence over the years $1817-29^{38}$ and culminating in a visit of Hegel to Weimar in the fall of 1827. Eckermann recorded the visit. He informs us that Goethe had a high esteem for Hegel personally but did not greatly appreciate some of the fruits of his philosophy, meaning by this his dialectics. Goethe feared that it might be abused for the purpose of turning falsehood into truth and truth into falsehood. Hegel answered, in a reply meant to be reassuring, that this sometimes happens, but only with spiritually sick people. ${ }^{39}$ History does not record whether Hegel perhaps defended his favorite philosophical child by pointing to the affinity of his dialectics with Goethe's (and Schelling's) favorite Polarität, but it does appear from his defense of Goethe's theory of color that he indeed approved of this concept.

If we now pass on to an examination of how Hegel defended Goethe, we must certainly award him the merit (if a merit it is) of having tried to integrate Goethe's theory of color into a larger philosophical framework. In doing so he made some of its features more relative and elaborated some others. The manner in which he contrived to do this may be summed up in three points:

First, nature itself is not, for Hegel, the ultimate reality it was for the pantheist Goethe. We have already mentioned in passing that Hegel was not a romantic nature-worshipper. To him-in a rather Gnostic waythe creation of Nature was a kind of Fall, not the fall of man Genesis speaks of but a Fall of God Himself. A necessary Fall, no doubt: Hegel's dialectical method guarantees that everything has its place as a necessary stage in the system, and is as such justified, but nevertheless.... The absolute idea decided "to externalize itself freely as Nature" (sich als Natur frei aus sich zu entlassen); and the reason is that, being essentially one and being turned inward, it needs as its antithesis that which is

${ }^{37}$ Letter to F. J. Seebeck (28 November 1812), quoted by M. J. Petry (HPN, I, 83). For Seebeck's relation to Goethe and to Hegel see also note 48 .

${ }^{38}$ To be found in Briefe von und an Hegel, ed. Johannes Hoffmann (Hamburg, 195254), II and III; and in Goethe-Hegel Briefwechsel, ed. Hermann Bauer (Stuttgart, 1970).

${ }^{39}$ J. P. Eckermann, Gespräche mit Goethe, 11. Originalauflage (Leipzig, 1910), 531f. 
essentially differentiated and turned outward, i.e., nature. So nature, although irrational and contingent, is nevertheless rational in a deeper sense, since it is dialectically linked to the idea. This rationality expresses itself in the laws of nature, but ultimately nature exists only in order to transcend itself at the end into the appearance of man and his history and thus to become spirit. The Philosophy of Nature is therefore the middle part of the triptychon that constitutes Hegel's system (the Science of Logic being the first and the Philosophy of Spirit being the final part). "Nature is implicitly divine in that it is the Idea; but in reality its being does not correspond to its Notion, and it is rather the unresolved contradiction." 40 And further: "If spiritual contingency or caprice goes forth into evil, that which goes astray is still infinitely superior to the regular movement of stars, or the innocent life of the plant, because that which errs is still spirit." 41 No doubt it was this depreciation of nature which had provoked Goethe's anger in 1812.

Second, light, though certainly homogeneous (Hegel here fully agrees with Goethe against Newton), is not simply taken for granted by Hegel as it is by Goethe, since its nature can only be properly understood within the context of philosophy of nature as a whole (just as nature can only properly be understood within the context of the system as a whole). The Philosophy of Nature itself is also a triptychon consisting of mechanics, physics, and organic physics. The latter describes the highest level nature can attain, namely, life (if only in its vegetable and animal form). With the phenomenon of light we leave mechanics (which describes matter in its abstractness) and enter the realm of physics (which deals with matter in its concreteness and its shaped individuality). Space and time constitute the general framework of mechanical phenomena: matter unites space and time, since it can only be thought of as matter-in-motion. ${ }^{42}$ Whereas space and time represent the external system of relations between material objects, attraction and repulsion represent a more internal relationship, the latter guaranteeing their being different, the former their underlying identity. Attraction and repulsion, however, ought not to be regarded as specific forces, acting independently of each other upon objects. They are nothing but the two inseparable aspects of the notion (Momente des Begriffes) of heavy matter. ${ }^{43}$ Matter is as such heavy; gravity should therefore be distinguished from mere attraction. Gravity, being the essence of matter, contains both aspects: attraction and repulsion. For gravity represents the eternal longing of matter for the unity it never attains (for

${ }^{40} H P N$, I, 209 f.

${ }^{41}$ Ibid.

${ }^{42}$ Ibid., 236ff. It is interesting again, that Schopenhauer gives in the Fourfold Root as well as in The World as Will and Representation a fairly similar theory of space, time and matter (cf. $S S W$, I, 29f. and II, 9ff.).

${ }^{43}$ Ibid., 242. 
then it would contract into one point) ${ }^{44}$ Whereas gravity thus reveals the unity of nature in a vague, obscure form, light does so in an ideal form, because it does not seek the unity but manifests it by its universal, uncorporeal nature. This is already sufficient reason to distrust the corpuscular theory of light and in fact the wave theory as well, since it supposes a quasi-material medium, however "ethereal" it may be (it should be noted that Goethe, too, considered the wave theory as just as mechanical and materialistic as Newton's corpuscular theory, and for the same reason, because its postulated "motion" still requires "something that moves").

Third, color certainly arises for Hegel from an interaction of light and darkness, as Goethe had taught. Although, in principle gravity is overcome by light, in reality the lower, mechanical level of nature continues to exist. Thus, there is an antithesis between light and dark, heavy matter, that hinders light's expansion and propagation. Once more this antithesis is a necessary one, since it is only through it that light becomes visible in the first place. "White is the corporal fixation of brightness, and is as yet achromatic; black is the materialization and specification of darkness; colour occurs between these two extremes. It is the combination of light and darkness, and particularly the specification of this combination, which first gives rise to colour." ${ }^{45}$ Hegel tries, however, to give a more elaborate explanation of this interaction, in particular of the role of the "turbid medium." Of central importance here is the phenomenon of transparency in connection with the nature of the four elements. Of these, only earth is opaque because of its abstract, material individuality, whereas air, water, and fire are transparent because of their elementary generality and neutrality. On the other hand, pure shape is transparent again, since it has attained once more that neutrality and uniformity which is related to the ideal nature of light.

That is why crystals are transparent; but whereas the transparency of the elements mentioned has to do with their lack of inner cohesion, the transparency of a crystal comes from the homogeneity of its coherent shape ${ }^{46}$ However, the different transparent media of light have all their particular nature, which expresses itself above all in their specific gravity. From this follows their greater or lesser density, which, in the case of water and air, is responsible for the phenomenon of refraction. ${ }^{47}$ In the case of crystals, this externally conditioned phenomenon gives place to an internally conditioned one. On the one hand crystals have a general transparency, but on the other hand they possess in their inner individualization or nuclear shape a form which deviates from the formal equality to which this general transparency belongs. It is this internal figuration

${ }^{44} H P N$, II, 19.

${ }^{45}$ Ibid., 142.

${ }^{46}$ Ibid., 12.

${ }^{47}$ Ibid., 125. 
of crystals which gives rise to the phenomenon of double refraction. ${ }^{48}$ In brittle glass, although it is still transparent, the process of inner individualization progresses from mere interior shape into actual interior splintering which constitutes the beginning of internal darkening (because the neutral nature of the crystal is now superseded) ${ }^{49}$ In the compactness of metallic being this potential darkness has progressed to actual darkness; metallicism therefore underlies the permanent colors of physical bodies. But apart from these "corporeal" colors, which are the result of inner darkening (Goethe's "objective" chemical colors), there are the "free" colors which are produced by external darkening, i.e., by the dimming effect of a translucent but turbid medium such as glass (Goethe's "objectivesubjective" physical colors).

The prism is the best known means for producing such a dimming effect. Its dimming action is the result of a twofold circumstance. It depends, first, upon its exterior boundary as such, in other words, upon its edges, and second, upon its prismatic shape, or the inequality in the diameters of its profile. Because of the latter, its dimming agency does not function uniformly but rather in accordance with the various lengths of its diameter between the various parts through which the light passes; ${ }^{50}$ therefore, it gives rise to different colors.

In this way Hegel claims to have demonstrated the fundamental soundness of Goethe's theory of color as against Newton's, of which he speaks with the utmost contempt. "According to Newton's well-known theory, white or colourless light consists of five or seven colours, the theory itself being not too clear on this point. It is impossible to denounce this barbarous manner of presentation too energetically. Even in its representation of light, it makes use of the concept of composition, which is one of the worst forms of reflection. What is more, brightness is supposed to consist of seven darknesses, which is about as sensible as saying that clear water consists of seven kinds of earth." 51 Hegel repeats Goethe's criticism of Newton's experimental method and also his triumphant reference to the achromatic telescope. One might expect, he says, that such blunders should have contributed to tone down Newton's absurd theories, but, alas, the contrary has happened: "they have recently been worked up into a further metaphysical gallimatias in the discoveries of Malus relating the polarization of light, in nothing less than the four-sidedness of sunbeams,

${ }^{48}$ Ibid., 133. Hegel had during the time that he lived in Nuremberg (1808-16) made the acquaintance with Thomas Seebeck, who was also Goethe's chief adviser in optical matters, and he had (like Goethe) taken an active part in Seebeck's experiments on the phenomena of polarized light. Hegel coined the name "entoptische Farben" for the color phenomena, appearing in double-refracting glass or crystal; the name was adopted by Goethe. Cf. Burwick, op. cit., 59.

${ }^{49}$ Ibid., 135.

${ }^{50}$ Ibid., 140.

${ }^{51}$ Ibid., 139. 
the rotatory movement of red light-corpuscles from right to left and of blue corpuscles from left to right...."52 As we have seen above, Hegel (like Goethe and their common adviser Seebeck) attributed the phenomenon of double refraction exclusively to the interior shape of the crystal. For him this was sufficient reason not only to scorn Malus's important investigations on the polarization of light but also to neglect all subsequent research in this field, which led to the discovery of interference and with that to the revival of the wave theory by Young and culminated in the work of Fresnel and his theory of transverse waves. But it is true that if you are $a$ priori certain that white light cannot be composite because "it is with light that we put aside the contemplation of separateness and plurality and have to raise ourselves to the abstraction of existent identity," 53 then this whole new development in the science of optics was indeed irrelevant; for these men of course agreed with Newton about the compositeness of white light. But are we not then entitled to ask, when reading Hegel's complaint in the Introduction to his Philosophy of Nature about the "extravagances" of Schelling's philosophy, ${ }^{54}$ whether the pot does not here call the kettle black?

The principal weakness of Hegel's enterprise lies in his attempt to defend Goethe's theory of color as a physical theory. This was certainly in line with Goethe's own conviction; and it is therefore not surprising that Goethe, in spite of his occasional fits of concern over the strictly philosophical aspects of Hegelianism, was rather content with his orthodox disciple. It was somewhat otherwise with that other disciple of his, to whom we turn now.

\section{Goethe and Schopenhauer}

It would be interesting to know whether Hegel and Schopenhauer ever acquainted themselves with each other's work on the theory of color. The only thing that can be said for certain is that Hegel must have known of Schopenhauer's contact with Goethe in the period of, roughly, 1813-16, and of the existence of Schopenhauer's little book On Vision and Color (Ueber das Sehn und die Farben) written in 1816, since Schopenhauer mentions both in the curriculum vitae he presented in 1819 to the University in Berlin in order to obtain the venia legendi. But while Hegel read the curriculum vitae, he probably never read On Vision and Color; nor is it likely that Schopenhauer ever made a serious study of his rival's contribution to this area of science. In any case this would only have served to lay bare to them their fundamental difference. For Schopenhauer's metaphysics (which he had not yet developed at that time) does not play

52 Ibid., 141.

${ }^{53}$ Ibid.

${ }^{54} H P N$, I, 192. 
any part in his optical studies; on the other hand his theory of knowledge (a virtually non-existent chapter in Hegel's philosophy) plays a crucial part. As I have tried to show in an earlier publication, it is in On Vision and Color rather than in the Fourfold Root that Schopenhauer's highly original theory of knowledge is stated for the first time-in fact, his optical studies made a decisive contribution to its genesis. ${ }^{55}$ And it is certainly this epistemological aspect of his theory of color which was largely responsible for Goethe's negative reaction to the manner in which his disciple had thought fit to defend the master's theory of color.

Schopenhauer had first made Goethe's acquaintance in the literary salon which his mother held in Weimar. The meeting went well enough, and young Arthur gladly accepted the admired poet's flattering invitation to collaborate in the field of optics, but before long he brought Goethe to the composition of the following impatient epigram: Trüg' gern noch länger des Lehrers Bürde/Wenn Schüler nur nicht gleich Lehrer würden. ${ }^{56}$ Thus, when Schopenhauer sent him the manuscript of On Vision and Color and asked Goethe to write a foreword, he politely but firmly refused. Schopenhauer gives the following explanation for the regretted rupture. "The amazing objectivity of his mind, which always gives his poetry the stamp of genius, is precisely what prevented him from returning to the subject, in this case, to the seeing eye itself, in order to pick up there the ultimate threads on which the whole phenomenon of the world of colours hangs; I, on the other hand, coming as I did from the school of Kant, was optimally prepared to satisfy this demand; so I was able, one year after having been withdrawn from Goethe's personal influence, to formulate the true, fundamental, and irrefutable theory of color."57 That's quite something! Yet this modest statement makes the essential point: Schopenhauer's epistemological background caused him to give a purely physiological interpretation of the phenomenon of color.

According to Schopenhauer, the fundamental error of all previous theories lies in their premature quest for the cause of the sensation of color without first having thoroughly studied the effect, i.e., color as a physiological phenomenon. Sensation as such is never something purely

${ }^{55}$ Cf. P. F. H. Lauxtermann, "Five decisive years: Schopenhauer's Epistemology as Reflected in His Theory of Colour," Studies in History and Philosophy of Science, 18 (1987), 271-91. It is to be regretted that Bryan Magee, in his admirable study on Schopenhauer's philosophy, ignores the profound differences between the first and the far better-known second version of The Fourfold Root. As a result he wrongly assumes that Schopenhauer stated his physiological interpretation of Kantian epistemology for the first time already in 1813 (the year of the publication of the first version of The Fourfold Root), whereas in fact he did not do so until in 1816 (the year of the publication of On Vision and Color). In the first version of The Fourfold Root this physiological interpretation is still wholly absent; it is therefore in Schopenhauer's optical studies that the origins of his epistemology are to be found, not the other way round (cf. Bryan Magee, op.cit., 98).

${ }^{56}$ Quoted by Schopenhauer himself in SSW, VI, 92.

${ }^{57}$ Ibid. 
passive; it is the reaction to a received stimulus. In the case of the eye the stimulus is light; the reaction is an activity of the retina. If the latter receives the full effect of light, it develops a full activity; if light is absent, i.e., if darkness reigns, the retina remains passive. Bodies which, under the influence of light upon them, act in their turn upon the eye with the same strength as light itself would do, are called "shining" or "mirrors" if they do so in concentrated form, and "white" if they do so in diffuse form. Bodies which, under the influence of light upon them, do not in their turn act upon the eye, are called "black." Therefore, white has essentially the same effect upon the eye as light; and this is why under the influence of either light or white the retina is fully active, whereas in the absence of both, i.e., in the case of either darkness or black, the retina is passive. Now the influence of light and of white on the retina and its resulting activity can occur in different degrees. Between the extremes of full activity and full passivity lie the domains of dimmed light (Halbschatten) and of grey, respectively. We may speak in this case of a quantitatively divided activity of the retina, which can itself be differentiated into intensively and extensively divided activity. The latter appears when the different parts of the surface of the retina are active to a different degree. This explains a phenomenon described by Goethe in the first section of the didactical part of his Farbenlehre (Physiologische Farben), namely, that a black cross on a white ground, after having been gazed at for a certain time, produces the opposite phenomenon, i.e., a white cross on a black ground, if we turn our eyes away from it and look on a grey or dim surface. Those spots on the retina that were affected by the white ground are now so exhausted by this stimulus that they cannot immediately be activated by the much weaker stimulus of the grey surface. This, in its turn, now acts with its full vigor upon the other parts of the retina that were previously affected by the black cross and consequently were at rest, and thus provokes the full activity of the retina.

But there is still a third possibility-qualitatively divided activity of the retina, the point at which color proper comes in. If you look intently at a white circle on a black ground for twenty to thirty seconds and then turn your eyes away to a light grey or dim surface, you will see a black cross on white ground for the reason given in the above. But if you put a yellow circle in place of the white one and then look at the grey surface, you will not see there a black circle but a violet one. Likewise an orange circle will produce a blue spectrum ${ }^{58}$; and a red circle ("red" in the Goethean sense, i.e., magenta) will produce a green spectrum and so on until the circle is closed. Schopenhauer's explanation of the phenomenon is as follows: yellow, being the brightest color, is somewhat darker than white; violet, being the darkest color, is somewhat brighter than black,

\footnotetext{
${ }^{58}$ The word "spectrum" is used by Schopenhauer in the Goethean sense of "afterimage."
} 
such that violet is as much brighter than black as yellow is darker than white. In consideration of the view that white corresponds to full activity of the retina and black to its full passivity, we may say that yellow corresponds to $3 / 4$ of the full activity and violet to $1 / 4$. Since the retina naturally aims at full activity, the impression of yellow produces a violet spectrum, which makes up for the missing quarter. Both colors are therefore complementary, forming a pair. Orange, being darker than yellow, is therefore farther removed from the full activity. It is as much darker than white as blue is brighter than black; both colors are in the proportion $2 / 3$ to $1 / 3$. They, too, form a pair of colors-a pair that also represents two unequal halves of the full activity. But red, being the darkest of the bright colors, and green, being the brightest of the dark colors, represent the two wholly equal halves of the full activity; they are therefore in the proportion of $1 / 2$ to $1 / 2$. This is the pair of colors where polarity is most evident; therefore they are generally considered the most harmonious colors. Schopenhauer frankly admits that his fraction-numbers cannot, strictly speaking, be demonstrated, but he holds them to be self-evident. Thus we get the following schema:

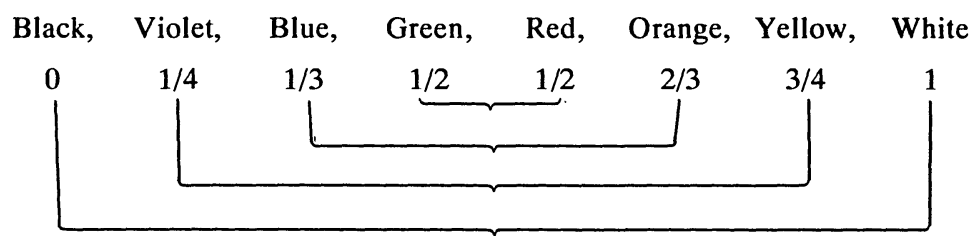

Since all colors are to a different degree brighter than black yet darker than white, they all contain both light and darkness. Therefore Goethe's conception of color as a synthesis of light and darkness is wholly correct; the only difference is that the synthesis is not of a physical but rather a physiological, and to that extent subjective, nature. ${ }^{59}$

And yet, Schopenhauer reluctantly admits, there is a sense in which Newton had been right. First, there is indeed a kind of division of light, even though this has to be sought in the eye rather than in light itself. It also follows from Schopenhauer's theory that under certain circumstances

${ }^{59} S S W$, I, 38. Schopenhauer here differs from Goethe in so far as he considers not yellow and blue but yellow and violet to be the original polar opposites; the growing thickness of the turbid medium then modifies them into orange and blue, respectively, and finally into red (= magenta) and green (in the latter he is in agreement with Goethe). 
white light can be produced out of a number of colored lights, only this number is two, not seven. For if, as Schopenhauer's theory asserts, two opposite colors are complementary in regard to the full activity of the retina to whose division they owe their existence, then there can be no doubt that the union of two such colors will produce that full activity and consequently the impression of pure light or of white. And indeed if we gaze at red and immediately thereupon at green, no spectrum will appear.

It would, however, be more convincing if this could also be demonstrated for physical colors. To that end it would be necessary that the two external causes of the two complementary colors could be made to act simultaneously and yet separately on the same spot of the retina. Now, this may be done with prismatic colors. If one lays the violet band of one prismatic spectrum over the red (i.e., prismatic red) band of a second one, the result will be "true" red (i.e., magenta); if one now directs the green band of a third prismatic spectrum toward that spot, that will appear as white. Goethe himself had made this experiment, but his polemic against Newton prevented him from accepting this result as conclusive evidence for the possibility of producing white light out of colored lights. Goethe's argument had been that in this case the threefold sunlight is powerful enough to make the element of darkness invisible, although it remains present. Yet this argument does not convince Schopenhauer, because if every color contains an element of darkness, as Goethe himself had taught, then in his experiment not only the element of light but the element of darkness, too, must be threefold; and so they neutralize each other. Therefore, it is not the increased illumination but rather the opposition of the colors which produces here the impression of pure light, or of white. It is this passage in particular which provoked Goethe's anger and made him regard his former disciple as an adversary. ${ }^{60}$ Wrongly, so Schopenhauer assures us, for this experiment does not at all demonstrate that Newton was right: it is only two colors, not seven, that in this case cover each other. Newton never understood the true, physiological, nature of color and thus attributed to light what in fact belongs to the activity of the retina. But it cannot be denied that Goethe himself went too far by rejecting any possibility of producing white out of colors. ${ }^{61}$

Yet in spite of Schopenhauer's assertion to the contrary, I am inclined to believe that Goethe's instinct had not deceived him. Of course Goethe was the last person to deny the importance of the beholding eye in the production of color phenomena. His Farbenlehre in fact opens with a chapter on Physiologische Farben (labeled by him as "subjective"), in which he discusses phenomena like after-images and colored shadows; and his later acquaintance with Purkinje's Beiträge zur Kenntnis des Sehens in subjektiver Hinsicht (1819) deepened his insight into the physiological

${ }^{60}$ Ibid., 45.

${ }^{61}$ Ibid., 52. 
implications of his own theory. But Goethe could not accept Schopenhauer's claim that in fact all of the Farbenlehre ought to be subsumed under Physiologische Farben, because Goethe's "objective-subjective" Physische Farben as well as his "objective" Chemische Farben also wholly depend on the subjective response of the retina for the interpretation of their stimulus in terms of "color." From his point of view this refusal was quite logical. It was not only the "amazing objectivity of his mind" which always urged him to see the eye itself as a product of Nature or, more precisely, as a "creature of Light" (Wär' nicht das Auge sonnenhaft ...); it was above all what he perceived as the dangerous consequences of Schopenhauer's approach. For Schopenhauer's purely physiological treatment of the phenomenon of color makes it in fact needless for him to oppose Newton's purely physical theory. When he pretends to adhere to Goethe's conception of the Urphänomen but at the same time tells us that Goethe's Urphänomen is not yet the real Urphänomen but only its cause, the real Urphänomen being the divided activity of the retina, ${ }^{62}$ he in fact makes nonsense of the whole conception, since an Urphänomen is evidently meant as something "ultimate," which can therefore not be "caused" by something else. Moreover, "darkness" (being the complete passivity of the retina) is for Schopenhauer (as it was for Newton) in fact something purely negative (namely, absence of light), whereas for Goethe it is the equal complement of "light."

What Schopenhauer describes is nothing loftier than an ordinary physiological phenomenon which, according to himself, must have an external (i.e., physical) cause; and he does not explain why, in serving this purpose, Goethe's theory of the turbid medium is to be preferred over Newton's theory. True, apart from the inevitable mentioning again of Newton's mistake about the impossibility of an achromatic telescope (cf. Goethe and Hegel), he does indeed point at some difficulties that would arise out of an attempt to reconcile Newton's physical theory and his own physiological theory. First, according to the latter, every color is one half of the qualitatively divided activity of the retina which has to be supplemented by another complementary, color in order to get full activity, so that there are in fact no single colors but only pairs of colors. This, together with the fact that all colors imperceptibly shade into each other and form a permanent circle, makes it impossible to accept a distinct number of colors, let alone an unequal one (Newton's seven colors). It is true, Schopenhauer admits, that Newton sometimes speaks instead of an infinite number of colors; but that is of no avail if you cling, with Newton, to the objective existence of colors in white light outside the eye. For in that case each color would either be in the same proportion of one to seven with

${ }^{62}$ Ibid., 70ff. Cf. also Burwick, op. cit., 66ff. For a critical evaluation of the whole of Schopenhauer's reception of the Farbenlehre see Karl Wessely, Goethes und Schopenhauers Stellung in der Geschichte der Lehre von den Gesichtsempfindungen (Berlin, 1922). 
white, which is not true, or (still more absurd) in the proportion of an infinitely small fraction to one, and thus disappear in its own darkness. It could be objected that Newton in fact did not say that colors exist in white light outside the eye. More interesting therefore is Schopenhauer's other argument, namely, that it would presuppose a very remarkable and strange harmonia praestabilita if the relationship between colors as it arises in the eye in accordance with the laws of the latter's functioning would have an exact objective counterpart outside the eye. ${ }^{63}$ But even accepting Schopenhauer's arguments against Newton's theory would not prove the validity of Goethe's theory; and indeed, in the Latin version of On Vision and Color which dates from 1830, Schopenhauer explicitly admits that his own theory is independent of Goethe's in so far as it would as a physiological theory still be true even if Newton and Goethe as physicists both had been wrong. ${ }^{64}$

It was Werner Heisenberg who once, when speaking of the GoetheNewton controversy, suggested the gentleman's solution that, since the two theories deal with two completely different levels of reality, they might complement rather than contradict each other: Newton's theory would stand for the "objective" and Goethe's for the "subjective" aspect of the matter. From the foregoing it might perhaps be concluded that Schopenhauer's modification of Goethe's theory would serve this end better than Goethe's own. Ironically enough, a similar claim has recently been made by M. J. Petry on behalf of Hegel, who for the sake of consistency (he says) should have treated Newton's theory of color in the Philosophy of Nature and should have given a separate account of Goethe's theory, for which the Philosophy of Subjective Spirit would have been the proper place. ${ }^{65}$ This too sounds plausible enough, but perhaps a little more could be said.

Now that every schoolboy knows that the very development of modern science has led to the abandonment of the mechanicist world-view, it has become quite the fashion to discover the startling actuality of one or another thinker of the past, who apparently already "foreshadowed" one or more of these developments. It might be (and has been) said, for example, that Hegel foreshadowed Maxwell by suggesting in his Philosophy of Nature a possible relationship between light, magnetism, and electricity, or that he, or that Schopenhauer, foreshadowed relativity by linking space and time; and it goes without saying that Schopenhauer did the same by pointing to the equivalence of "Will" (which might be somewhat freely translated as "energy") and matter and by rejecting either as a "wholly metaphysical entity." But our enthusiasm would somewhat be

${ }^{63}$ Ibid., 66ff.

${ }^{64}$ Theoria colorum physiologica, eademque primaria (Ibid., 3).

${ }^{65}$ HPN, II, 369. 
dampened by a closer inspection of the context, especially Schopenhauer's failure to see, like Hegel and like Goethe, the importance of the work of physicists like Arago and Fresnel-mentioned by him in the second edition (1854) of On Vision and Color-and his dismissal of the wave-theory as just another version of Newtonianism. ${ }^{66}$ This should make us cautious with such statements. To give a more concrete example: it seems obvious to suggest that Schopenhauer's theory of the divided activity of the retina prepared the way for the Young-Helmholtz theory of color-vision with its three kinds of color-responsive receptors in the eye, which can be equally stimulated, but also only one or two of them. But this would overlook two important differences. First, this theory is linked physically to the wave-theory of light and physiologically to the exhaustion-theory, rejected explicitly by Schopenhauer in a polemical passage against the Jesuit Carl Scherffer, as far as the "qualitatively" divided activity of the retina, i.e., color vision, is concerned. ${ }^{67}$

Moreover, there is no trace of actual influence of Schopenhauer here, or in natural science generally, and the same is true of Hegel. Both thinkers have been highly influential, but their influence lies in wholly other fields. Returning to Heisenberg's suggestion of a possible synthesis of Newton's and Goethe's theory of color, it may be that such a synthesis could have been realized already by Hegel or by Schopenhauer, but the fact remains that neither of them did realize it. Yet I would suggest that Schopenhauer has a somewhat better claim to the title, for he made at least the first step, specifically to modify Goethe's theory of color into a vision that takes the perceiving subject as its starting-point. Moreover, his metaphysical system contained no element that would have prevented him from taking the second step as well, namely, to accept Newton's physical theory, even if in modified form.

It was otherwise with Hegel. Petry's claim on behalf of Hegel overlooks that the metaphysical status of light in Hegel's philosophy of nature implied the obligation, in Hegel's words, "to think in an ideal manner about light"; and since for him this excluded any thought of "composition" ("the worst form of reflexion" and "the crudest of metaphysical propositions"), ${ }^{68}$ it was a priori impossible for him to integrate Newton's theory in his system. Such a metaphysical obstacle did not exist for Schopenhauer; but it is a fact that the subjectivist nature of his epistemology, which made him immune against any kind of naive realism, also prevented him from considering the possibility of a combination of Newton's physical theory with his own physiological theory. His remark, quoted above,

${ }^{66} S S W, \mathrm{I}, 88$. The absurdity of the wave-theory is already demonstrated, according to Schopenhauer, by the circumstance that the most dull color (violet) corresponds there to the greatest frequency and the most vivid color which makes even animals furious (red) to the lowest frequency.

${ }^{67}$ Ibid., 48.

${ }^{68} H P N$, II, 141. 
on the odd harmonia praestabilita such a combination would imply, makes this quite clear. Should our conclusion then be that both thinkers failed, albeit for different reasons, and thus demonstrated, each in his own way, the futility of all attempts towards a philosophy of nature?

Such a conclusion would be as historically unjust as it would be premature. It is easy for us to say that thinkers like Hegel and Schopenhauer fought a rear-guard battle in the wake of Goethe and Romanticism, when they tried to put mathematical science into its proper place by insisting that only simple mechanical phenomena lend themselves to mathematical treatment. Certainly the mathematization of science has made triumphant progress since, but that does not mean that the romantic protest against the (often unconscious) metaphysics of the science of their time (the quantitative world of "primary qualities" as the true world behind the deceptive qualitative world of human sense and feeling) was without justification, nor that the mathematical language of science provides the only legitimate tool for the eternal quest of the human mind of "was die Welt im Innersten zusammenhält."

Moreover, I think that we should differentiate here once more between our two thinkers. Neither of them was a romantic Nature-worshipper, both accorded to ("positivistically" understood) science a legitimate role but thought that it should be augmented by a metaphysical "superstructure," and both insisted on the existence of varying levels of complexity as regards the subject-matter of the various sciences and therefore on a hierarchy between them. Their fundamental difference was expressed in the most striking way by Schopenhauer himself. The Biblical myth of creation shares one fundamental illusion with Hegel's interesting story about an Idea that decides "to externalize itself freely as Nature." This illusion is, according to Hegel, that the whole of things has its origin in an intellect, in other words, existed already as mere representation (Vorstellung) before becoming real; and that, because of its origin in knowledge, it is consequently also wholly accessible to and understandable and exhaustible by knowledge (if not by the trivial knowledge of Verstand, then at least by the higher knowledge of Vernunft).$^{69}$ It is indeed more than a mere question of words when Hegel turns the "Idea" and Schopenhauer the "World as Will" into the central tenet of his metaphysics. For both logic stands methodologically at the beginning because of the elementarity and abstractness of its subject-matter; but for Schopenhauer its role is played out with that, whereas Hegel claims a quasi-ontological status for his new, "dialectical" brand of logic. For Hegel logic is "the presentation of God as He was in His eternal essence before the creation of Nature and finite Spirit," omega of his essentially circular system.

${ }^{69}$ SSW, VI, 101.

${ }^{70}$ Hegel, Jubiläumausgabe, IV, 46. 
This throws light, too, on the different reasons why neither of them was a romantic nature-worshiper: ethical reasons for Schopenhauer (the omnipresent Will is far from being something venerable), intellectual reasons for Hegel (as in his remarks in the Introduction to the Philosophy of Nature). ${ }^{71}$ For Schopenhauer nature is anyhow an awe-inspiring force and reason only a late product of nature. For Schopenhauer reason seems too imperfect to grasp nature adequately, whereas for Hegel nature is too imperfect to embody the idea of reason adequately. Is Schopenhauer's skeptical attitude, in spite of its apparent irrationalism, not nearer to the true scientific spirit than Hegel's panrationalism? It is, in my opinion, precisely this romantic realism which gives Schopenhauer his unique place in the history of philosophy and his significance for the contemporary reader as well.

University of Twente.

${ }^{71}$ See above, at n. 40. 